\title{
Erratum to: Evolutionary fate of SVA2 elements in primate genomes
}

\author{
Yongsik Kwak • Yun-ji Kim • Jinchuan Xing • \\ Kyudong Han
}

Published online: 6 December 2014

(C) The Genetics Society of Korea and Springer-Science and Media 2014

\section{Erratum to: Genes Genom}

\section{DOI 10.1007/s13258-014-0241-6}

There are some errors in the original publication of this article.

The 1st author's name was misspelled. The name should be Yongsik Kwak, not Yonsik Kwak.

In Table 1, the legend is missing and the contents are changed.
In Acknowledgement, the funding year should be 2014, not 2013.

Please find the correct author's name, Table 1, and Acknowledgment in this erratum

Acknowledgments The present work was conducted with funding from the Research Fund of Dankook University in 2014.

The online version of the original article can be found under doi:10.1007/s13258-014-0241-6.

Y. Kwak $\cdot$ Y. Kim $\cdot$ K. Han $(\bowtie)$

Department of Nanobiomedical Science \& BK21 PLUS NBM

Global Research Center for Regenerative Medicine, Dankook

University, Cheonan 330-714, Republic of Korea

e-mail: kyudong.han@gmail.com

Y. Kwak · Y. Kim · K. Han

DKU-Theragen Institute for NGS Analysis (DTiNa),

Cheonan 330-714, Republic of Korea

J. Xing

Department of Genetics, Rutgers, The State University of New

Jersey, Piscataway, NJ 08854, USA

J. Xing

Human Genetics Institute of New Jersey, Rutgers, The State

University of New Jersey, Piscataway, NJ 08854, USA 
Table 1 Summary of SVA2 elements in the primate genomes

\begin{tabular}{|c|c|c|c|c|c|}
\hline \multirow[t]{2}{*}{ Classification } & \multicolumn{5}{|c|}{ Number of loci } \\
\hline & Human & Chimpanzee & Gorilla & Orangutan & $\begin{array}{l}\text { Rhesus } \\
\text { macaque }\end{array}$ \\
\hline Blat results & 196 & 196 & 195 & 204 & 150 \\
\hline $\begin{array}{l}\text { Discarded after } \\
\text { manual inspection }\end{array}$ & 52 & 57 & 65 & 66 & 34 \\
\hline $\begin{array}{l}\text { Confirmed SVA2 } \\
\text { elements }\end{array}$ & 144 & 139 & 130 & 138 & 116 \\
\hline $\begin{array}{l}\text { Confirmed by } \\
\text { PCR analysis }\end{array}$ & - & - & 6 & 1 & - \\
\hline Total & 144 & 139 & 136 & 139 & 116 \\
\hline
\end{tabular}

